\title{
Hungry Bone Syndrome Associated with Transient Hypoparathyroidism
}

Al Omran $\mathrm{HI}^{1}$, Al-Jurayyan $\mathrm{A}^{2}$, Alissa $\mathrm{SD}^{3}$, Babiker $\mathrm{AM}^{3}$, Al-Jurayyan $\mathrm{NA}^{3 *}$

${ }^{1}$ Pediatric Department, College of Medicine, Sattam bin Abdulaziz University, Kharj, Saudi Arabia.

${ }^{2}$ Orthopedic Departments, College of Medicine, King Saud University, Riyadh, Saudi Arabia.

${ }^{3}$ Endocrinology Unit, Department of Pediatrics, College of Medicine, King Saud University, Riyadh Saudi Arabia.

\section{Abstract}

We report on an infant who presented at 50 days old of age with hypocalcemic seizure, who proved to have transient hypoparathyroidism, biochemically. During the course of his therapy, he developed severe hungry bone syndrome. Hungry bone syndrome and transient hypoparathyroidism is highlighted.

Keywords: Hypoparathyroidism; Hungry Bone Syndrome; Infant; Transient.

\section{Introduction}

Hypoparathyroidism is a state of inadequate parathyroid hormone (PTH). It results from defective synthesis or secretion of PTH, end organ resistance, or inappropriate regulations. Hypoparathyroidism may be transient, genetically inherited or acquired. Transient usually occurs during neonatal period or secondary to medication. The ionized calcium concentration, in extra cellular fluid (ECF), falls bellow reference range, where at birth parathyroid gland have a limited ability to respond to decrease in serum calcium [1-4]. The term "hungry bone syndrome" HBS has been coined to the profound, serum calcium of less than 2.1 mmol and prolonged hypocalcemia. The severe hypocalcemia is believed to be due to deposition of calcium in bones $[5,6]$.

We present an infant with transient hypoparathyroidism who developed sever hungry bone syndrome. Such an association is highlighted.

\section{Case Presentation}

A full term, 50 day-old Saudi male boy, presented to the emergency department with afebrile tonic-clonic seizure lasting for several minutes and aborted by rectal diazepam. Pregnancy and neonatal history was unremarkable, in particular the mother was not on any medication. No family history of seizure disorder. He was appropriate for age and there was no dysmorphic features.

Initial serum calcium (Ca) was low at $1.4 \mathrm{mmol}$ (normal 2.2 - 2.5 ) inorganic phosphate (P) $3.25 \mathrm{mmol}$ (normal 1.4 -2.1), and alkaline phosphatase activity (ALP) $150 \mathrm{U} / \mathrm{L}$ (normal <600), serum magnesium $(\mathrm{Mg}) 1.4 \mathrm{mmol} / \mathrm{L}$ ( normal 0.8 - 1.6 ), parathyroid hormone (PTH) was $0.127 \mathrm{pmol} / \mathrm{L}$ ( normal 1.6 - 6.9), and 25 hydroxy vitamin D $75 \mathrm{nmol} / \mathrm{L}$ ( normal > 50). Normal chest x ray, and normal echocardiogram. The child was not septic. Mother's bone profile, 25 hydroxy vitamin D and PTH concentration were normal.

The patient was initially managed with intravenous calcium infusion, then later with oral calcium $(50 \mathrm{mg} / \mathrm{kg} /$ day) in four divided doses and calitriol (1,25 dihydroxycholecalciferol ). Three week later re-admitted again with afebrile seizure, serum calcium was $1.2 \mathrm{mmol} / \mathrm{L}$ (normal 2.2 - 2.5). He require high dose of calcium $(200 \mathrm{mg} / \mathrm{kg} /$ day), in addition to calcitriol. No further seizure, and was discharged after one week of hospitalization on calcium and calcitriol, with serum calcium of $2.3 \mathrm{mmol} / \mathrm{L}$, subsequently he was followed in the endocrine clinic, and within three months his medication were gradually withdrawn. He continued to be well

\section{*Corresponding Author:}

Nasir A.M. Al-Jurayyan MD,

Professor and Senior Consultant Pediatric Endocrinologist, Division of Endocrinology, Department of Pediatrics, College of Medicine, King Saud University, Riyadh Saudi Arabia. Tel: 0505400592

E-mail: njurayyan@gmail.com

Received: May 19, 2017

Accepted: July 06, 2017

Published: July 07, 2017

Citation: Al Omran HI, Al-Jurayyan A, Alissa SD, Babiker AM, Al-Jurayyan NA (2017) Hungry Bone Syndrome Associated With Transient Hypoparathyroidism. Int J Clin Ther Diagn. 5(1), 134-135. doi: http://dx.doi.org/10.19070/2332-2926-1700025

Copyright: Al-Jurayyan NA ${ }^{\circ}$ 2017. This is an open-access article distributed under the terms of the Creative Commons Attribution License, which permits unrestricted use, distribution and reproduction in any medium, provided the original author and source are credited. 
off therapy with serum calcium ranging between $2.2-2.4 \mathrm{mmol} /$ $\mathrm{L}$, and serum concentration of PTH $3.2 \mathrm{pmol} / \mathrm{L}$ (normal 1.6 6.9). At time of reporting the case, he is currently 5 years of age with normal bone profile and PTH serum concentration. He is neurodevelopmentally appropriate for age.

\section{Discussion}

Hypoparathyroidism is a state of inadequate parathyroid hormone (PTH), which results from defect in synthesis, secretion, unresponsive end organ, or inappropriate regulation of the hormone. It could be transient usually in the neonatal period or associated with use of some medications as in amphotericin B, which can lead to hypomagnesia which is an important cofactor for parathyroid hormone. The diagnosis of transient hypoparathyroid, in our patient, was established on basis of low PTH and calcium, with high phosphate and normal alkaline phosphatase, which returned to normal after three months of therapy. The infant did not receive any medications such as amphotericin B nor had hypo or hypermagnesia. The mother did not have hyperparathyroidism and she never consumed alcohol, or were on any medications containing calcium. Maternal hyperparathyroidism causing hypercalcemia during pregnancy and can suppress fetal and neonatal parathyroid hormone (PTH) secretion. As a consequence, transient neonatal hypoparathyroidisim can occur in an infant born to a mother with untreated hyperparathyroidism [1-4, 7-11]. Hungry bone syndrome was first reported in 1948. Extensive mineralization of the bone, reflecting deposition of calcium and phosphate within the bone parenchyma [12]. Our patient required a very high dose of oral calcium with no clinical evidence of malabsorption. Hungry bone syndrome should be considered in differential diagnosis of hypocalcemia. Close monitoring of calcium with aggressive calcium replacement at the earliest is essential to prevent neuromuscular complications and seizures. Earliest detection of the risk factors for HBS and treatment with calcitriol/biphosphonate may reduce potentially life threatening hypocalcemia in similar patients.

Hungry bone syndrome is a clinical entity which is accompanying hypocalcemia and hypomagnesemia resulting from an increase in bone formation. It is related to a pathological scenario which causes an imbalance between osteoclast mediated bone resorption, and osteoblast mediated bone formation, favoring the latter due to plasmatic calcium level reduction $[5,6,12,13]$.

\section{Conclusion}

Hungry bone syndrome is a well known entity associated with treatment of hypocalcemia. Continuous and frequent serum calcium monitoring is mandatory to avoid the two extreme complications, hypo and hypercalcaemia.

\section{Acknowledgement}

The authors would like to thank Ms. Hadeel N. Al-jurayyan for her help in preparing this manuscript.

\section{References}

[1]. Tseng UF, Shu SG, Chen CH, Chi CS (2001) Transient neonatal hypoparathyroidisim: report of four cases. Acta Pediatric Taiwan. 42(6): 359-62.

[2]. Roth KS, Ward RJ, Chan JC, Sarafoglou K (2009) Disorder of calcium, phosphate and bone metabolism. Pediatric Endocrinology and inborn error of metabolism. New York, NY, Mc Graw Hill. 619-64.

[3]. Marcus, Garty BZ (2011) Transient hypoparathyroidism due to Amphotericin B induced hypomagnesemia in a patient with beta thalassemia. Ann Pharmacother. 35(9): 1042-1044.

[4]. Laitinen K, Lamberg-allardt C, Ylikahri R, Tunninen R, Karonen SL, et al., (1991) Transient hypoparathyroidism during acute alcohol intoxication. N Engl J Med. 324(11): 721-7.

[5]. Hisham AN, Aina EN, Zanariah H (2000) Recognition and management of hungry bone syndrome in a case report. Med j Malaysisa. 55(1): 132-134.

[6]. Demirci H, Suyani E, Karakoc A, Toruner Fb, Yetkin I, et al., (2007) A longstanding hungry bone syndrome. Endocrinologist. 17: 10-12.

[7]. Hsu SC, Levina MA (2004) Perinatal calcium metabolism: physiology and pathophysiology. Semin neonatal. 9(1): 23-36.

[8]. Thomas TC, Smith J, White PC, Adhikan S (2012) Transient neonatal hypocalcemia: presentation and outcomes. Pediatric. 129(6): e1461-e1467.

[9]. Shoback D (2008) Clinical practice. Hypoparathyroidism. N Engl J Med. 359(4): 391-403.

[10]. De sanctis V, Soliman A, Fiscina B (2012) hypoparathyroidism; from diagnosis to treatment. Curr opin Endocrinol Diabetes Obes. 19(6): 435-42.

[11]. Al Azem J, Khan AA (2012) Hypoparathyroidism. Best Pract Res Clin endocrinol metab. 26(4): 517-22.

[12]. Albright F, Reifenstein EC (1984) The parathyroid gland and metabolic bone disease. Williams and Wilkins, Balltimore.

[13]. Witteveen JE, Van Thiel S, Ramijn JA, Hamdy NAT (2013) Therapy of endocrine disease: hungry bone syndrome: still a challenge in post-operative management of primary hyperparathyroidism a systemic review of the literature. Eur J Endocrinol. 168: R45-R53. 